\title{
Rubella in Sub-Saharan Africa and sensorineural hearing loss: a case control study
}

\author{
Cristina Caroça ${ }^{1,2,3^{*}}$ De, Vera Vicente ${ }^{4}$, Paula Campelo ${ }^{2}$, Maria Chasqueira ${ }^{4}$, Helena Caria ${ }^{5,6,7}$, Susana Silva ${ }^{1,3}$,
} Paulo Paixão $0^{4,8}$ and João Paço ${ }^{1,2}$

\begin{abstract}
Background: Rubella infection can affect several organs and cause birth defects that are responsible for congenital rubella syndrome (CRS). Congenital hearing loss is the most common symptom of this syndrome, occurring in approximately $60 \%$ of CRS cases. Worldwide, over 100000 babies are born with CRS every year. There is no specific treatment for rubella, but the disease is preventable by vaccination. Since 1969, the rubella vaccine has been implemented in many countries, but in Africa, only a few countries routinely immunize against rubella. The aim of this study was to estimate the rate of infection from the wild-type rubella virus in São Tomé and Príncipe by determining rubella seroprevalence with a DBS method. The goal of this study was to reinforce the need for implementation of the rubella vaccine in this country. As secondary objectives, the validation of a DBS method was first attempted and an association between seroprevalence and hearing loss was assessed.
\end{abstract}

Methods: We collected samples from individuals observed during humanitarian missions in São Tomé and Príncipe. All individuals underwent an audiometric evaluation, and a drop of blood was collected for the dried blood spot (DBS). We define two groups: the case group (individuals with unilateral or bilateral hearing loss $(\mathrm{HL})$ ) and the control group (individuals with two normal ears). Patients were excluded if they suffered from conductive $\mathrm{HL}$, if they showed evidence of possible causes of $\mathrm{HL}$, if they had developmental delay or if they refused to participate in the study.

Results: Among the 315 subjects, we found $64.1 \%$ individuals with IgG for the rubella virus, $32.1 \%$ without immunity for the rubella virus and $3.8 \%$ who were borderline.

In the control group, $62.6 \%$ were positive for the rubella lgG, whereas in the case group, $72 \%$ were positive. Analyzing both groups, with ages ranging from 2 to 14 years of age and from 15 to 35 years of age, we found a seroprevalence of $50.3 \%$ to rubella in the younger group and $82.1 \%$ in the older group, with a significant difference between cases and control group noted within the younger patients $(p=0.025)$.

Conclusions: Rubella is a disease that can be prevented. Rubella infections are still very common in São Tomé and Príncipe, and women of child-bearing age are still at risk for rubella infection during pregnancy, justifying the urgency of vaccination against rubella.

A statistically significant association between the group of children under 14 years of age with $\mathrm{HL}$ and immunity for rubella was observed in this country, although this study did not allow us to establish a cause-effect relationship between rubella infection and SNHL.

Keywords: Rubella, Hearing loss, Sub-Saharan Africa, Congenital Rubella Syndrome, World Health Organization

\footnotetext{
* Correspondence: cristinacaroca@netcabo.pt

'Otolaryngology Department, NOVA Medical School/Faculty of Medical

Sciences, Universidade Nova de Lisboa, Campo dos Mártires da Pátria, 130,

1169-056 Lisboa, Portugal

${ }^{2}$ Hospital CUF Infante Santo, Avenida Infante Santo, 34, 6 $1350-079$ Lisboa,

Portugal

Full list of author information is available at the end of the article
}

(c) The Author(s). 2017 Open Access This article is distributed under the terms of the Creative Commons Attribution 4.0 International License (http://creativecommons.org/licenses/by/4.0/), which permits unrestricted use, distribution, and reproduction in any medium, provided you give appropriate credit to the original author(s) and the source, provide a link to the Creative Commons license, and indicate if changes were made. The Creative Commons Public Domain Dedication waiver (http://creativecommons.org/publicdomain/zero/1.0/) applies to the data made available in this article, unless otherwise stated. 


\section{Background}

Primary rubella infection during pregnancy, particularly during the first trimester, can affect several organs and cause birth defects that are responsible for congenital rubella syndrome (CRS) [1]. The most common defects of CRS are hearing impairment (unilateral or bilateral sensorineural), eye defects (e.g., cataracts, congenital glaucoma, or pigmentary retinopathy), and cardiac defects (e.g., patent ductus arteriosus or peripheral pulmonic stenosis). Congenital hearing loss is the most common sequela, occurring in approximately $60 \%$ of cases, especially when infection occurs in the 4th month of pregnancy [2]. In a Brazilian study, congenital rubella was thought to be the cause of hearing loss in $32 \%$ of patients with deafness [3], and in studies conducted in sub-Saharan Africa, rubella was considered to be one of the causes of HL [4].

The Global Measles and Rubella Strategic Plan (20122020) included goals to eliminate rubella and CRS in at least two WHO regions by 2015 as well as in at least five WHO regions by 2020. However, in this plan, the African region does not have a specific target. The number of rubella cases reported from 2000 to 2014 increased in the African region (from 865 cases in seven countries to 7402 cases in 44 countries). Although the rubella vaccine has been implemented in many countries since 1969, worldwide coverage is still a distant goal, particularly in Africa, where only a few countries routinely immunize against rubella $[5,6]$.

The efficacy of the vaccine is approximately $95 \%$, without significant side effects [7]. In 2015, the Americas region was the world's first region to eliminate rubella and CRS. In Europe, all 53 Member States of the WHO European Region committed in 2010 to the goal of interrupting the endemic transmission of measles and rubella by 2015 , which was not yet achieved in all regions. However, many states, including Portugal, have already interrupted the endemic transmission of rubella [8].

The São Tomé and Príncipe islands are within the Atlantic in sub-Saharan Africa, located at the level of the Equator. It is an underdeveloped country with few economic resources that survives through external support, including humanitarian service. As part of a humanitarian project on the islands of São Tomé and Príncipe, the "Health for All" system of Institute Marquês Valle Flor (IMVF) has been implemented to improve the primary and secondary health care of the population. This project includes doctors of several specialties, including otolaryngology.

During these tasks, an increased prevalence of sensorineural hearing loss (SNHL) cases was initially noted, particularly in the younger age group [9]. CRS cannot be excluded as a possible etiology of SNHL and is one of several possible causes.
The epidemiology of rubella is not known in this country, and there is no vaccine implementation [10] nor is there the possibility of diagnosis through laboratory tests.

The aim of this study is to estimate the rate of infected people with wild-type rubella virus in São Tomé and Príncipe by determining rubella seroprevalence through the DBS method to reinforce the need for vaccine implementation in this country. As secondary objectives, the validation of a DBS method was first attempted and an association between seroprevalence and hearing loss was also evaluated.

\section{Methods}

\section{Subjects}

The samples studied were collected between January and May of 2014 from individuals who presented for an audiology consultations at the Hospital Ayres de Menezes on São Tomé Island and the Hospital Dr Manuel Quaresma Dias da Graça on Principe Island during humanitarian missions. Samples were also collected from students and workers from a hotel. All participants in the study were natives and residents of the islands. In total, we analyzed 315 samples collected from individuals 2 to 35 years old. Of these, 171 individuals were female and 144 were male. All individuals underwent audiometric evaluation (tonal audiogram or auditory brainstem response measurements) according to the degree of collaboration, having adapted the results of the auditory brainstem response (ABR) to audiometric thresholds according to standards [11].

We defined two groups based on the WHO classification [12]. The case group was composed of individuals with hearing loss, in which we included individuals with unilateral HL or both ears with HL. The control group included individuals with two normal ears.

All patients answered a questionnaire about selfreported HL and clinical history. There are no clinical registries about these patients in any hospital from São Tomé or Príncipe.

Patients were excluded if they suffered from conductive deafness, showed evidence of possible causes of $\mathrm{HL}$, had developmental delay, or did not give consent to participate in the study.

In addition to the audiometric evaluation, a drop of blood was collected via venous or capillary puncture and blotted onto filter paper. After collection, the blood spots were dried at room temperature for $24 \mathrm{~h}$ (Dried blood spot-DBS). The IgG measurement was carried out in Portugal after 9 months (during which the samples were stored at room temperature).

The project was submitted to and approved by the Medical Ethics Committee of STP and Ethics Research Committee NMS|FCM-UNL ( $\left.{ }^{\circ} 02 / 2014 / C E F C M\right)$. The 
Ethics Research Committee is aligned with the Declaration of Helsinki for the Protection of Human Subjects. A full consent process was applied for all participants. Consent to use the survey data was also obtained.

\section{Technical validation of the rubella IgG determination}

The procedure of IgG determination from DBS was validated and optimized by two approaches: 1) First, samples were collected from 20 pregnant women at the Hospital da Luz, Portugal. We simultaneously collected blood samples for DBS and for serum. The specificity and sensitivity of the IgG determination from DBS were evaluated compared to the standard method (IgG determination from serum). 2) Second, 15 DBS samples were collected in 10 children between 1 and 10 years of age (who were vaccinated against rubella) and 5 children between 9 and 12 months of age (who were not vaccinated against rubella). In this group, IgG determination from DBS was correlated with the immune status (vaccinated / unvaccinated).

The extraction protocol for IgG in DBS was tested with three different volumes of diluent $(200 \mu \mathrm{L}, 400 \mu \mathrm{L}$, and $800 \mu \mathrm{L}$ ) in this validation step, while the protocol for the determination of the serum IgG was recommended by the SERION ELISA classic rubella virus IgG kit. Both the extraction and IgG ELISA protocols are described below.

\section{Rubella IgG determination from the São Tomé and Príncipe population}

Rubella IgG extraction: For the IgG extraction, we added $400 \mu \mathrm{L}$ of SERION ELISA kit dilution solution to $1 / 4$ of the DBS, corresponding to $32 \mathrm{~mm}^{2}$. The extraction was carried out for $60 \mathrm{~min}$ at $600 \mathrm{rpm}$ at room temperature and $18 \mathrm{~h}$ at $4{ }^{\circ} \mathrm{C}$.

Rubella IgG determination: The SERION ELISA classic rubella virus IgG kit was used for this determination. We performed the protocol recommended by SERION. Briefly, $100 \mu \mathrm{L}$ of the control, standard and extracted samples were pipetted into a 96 well microplate (only one sample per patient was tested). The microplate was then incubated at $37{ }^{\circ} \mathrm{C}$ for $60 \mathrm{~min}$ in a humid chamber and washed 3 times with wash solution $(300 \mu \mathrm{l})$. Then, the IgG conjugate $(100 \mu \mathrm{l})$ was added and the microplate was incubated under the same conditions, after which the washing process was repeated. Subsequently, the substrate $(100 \mu \mathrm{l})$ was added and the incubation process was repeated. Finally, we added a stop solution $(100 \mu \mathrm{l})$, and the optical density was read at $415 \mathrm{~nm}$ against $630 \mathrm{~nm}$. The optical densities were converted into UI through the Serion Activity V11 program, with the following interpretation: negative: <10UI; borderline; 10 15UI;positive $>15 \mathrm{UI}$.
The results were interpreted according to the algorithm shown in Fig. 1.

\section{Statistical processing of the data}

Sample descriptions were made using descriptive statistics, considering the frequency analysis, means and standard deviations (SDs).

To study the association between IgG rubella in the case/ control group and each of the following parameters, age group, district origin, oral language, gender and $\mathrm{HL}$, the chi-square test was used by Monte Carlo Simulation.

To identify the risk factors of HL, we adopted a Binary Logistic Regression, where HL is a response variable. The independent variables were the IgG rubella and age groups.

All analyses were performed using the Statistical Package for the Social Sciences for Mac version 20.0 (SPSS).

\section{Results}

Technical validation of the rubella IgG determination

The sensitivity and specificity for each of the different volumes of diluent tested, when compared with the standard method were, 100 and $50 \%(200 \mu \mathrm{L}), 89$ and $100 \%(400 \mu \mathrm{L})$ and 72 and $100 \%(800 \mu \mathrm{L})$. According to these results, a volume diluent of $400 \mu \mathrm{L}$ was chosen for the determination of Rubella IgG in the São Tomé and Príncipe populations.

The DBS method also showed a good correlation (100\%) with the immune status (vaccinated/unvaccinated). The ten vaccinated children were positive for the IgG while the five unvaccinated children were negative for IgG.

\section{Rubella IgG determination from São Tomé and Príncipe population}

We evaluated 315 subjects (Table 1), from 2 to 35 years of age, of whom 144 (45.7\%) were men and 171 (54.3\%) were women, with a mean age of $17.36 \pm 9.734$ years.

Among the 315 subjects, we found 202 (64.1\%) individuals with IgG for the rubella virus. Of these, 101 (32.1\%) did not have immunity to rubella and $12(3.8 \%)$ were borderline. Borderline cases were excluded from the study.

In the sample, we did not find any statistical significance for gender $(p=0.391)$, resident district $(p=0.061$, or chi-squared test by Monte Carlo simulation), family history of HL $(p=0.207)$, or consanguinity $(p=0.461)$.

We established two groups concerning hearing status: a control group with patients with normal hearing in both ears and a case group with at least one ear with sensorineural hearing loss (SNHL).

In the control group, we found $62.6 \%$ of positive immunity to rubella, whereas in the case group, positive 


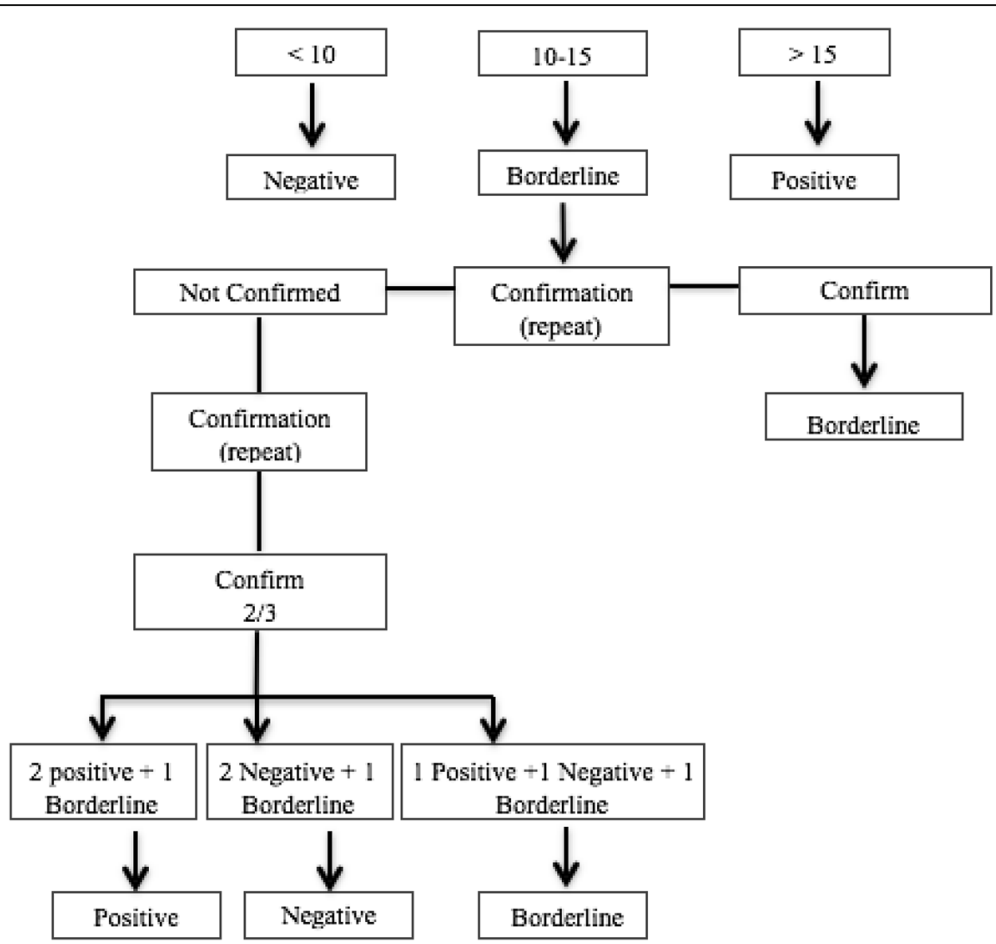

Fig. 1 Algorithm for the interpretation of the results. The results are expressed in international units (U/I)

immunity was $72 \%$. There was not a significant difference between the case and control groups $(p=0.085)$.

Analyzing both the 2-to-14 years of age group and the 15-to-35 years of age group, we found a seroprevalence of $50.3 \%$ to rubella in the younger group and $82.1 \%$ in the older group, with a significant difference between the case and control groups within the younger group $(p=0.025)$ but not within the older group $(p=0.528)$ (Table 2).

By applying the binary logistic regression model, positive immunity to rubella was identified as a risk factor for HL (Table 3). Positive immunity to rubella almost doubled the risk of HL (OR =1.776; CI 95\% [1.0503.004]) when analyzed with the age groups, but without any statistical significance in these age groups. Therefore, immunity to rubella was associated with $\mathrm{HL}$.

A higher prevalence of "no oral language" was found in the case group compared to the control group ( $p=$ $0.0001)$.

\section{Discussion}

Since their first diagnostic application almost five decades ago, DBSs have been employed in many research areas and in clinical applications for several viruses, including Human immunodeficiency virus, Hepatitis C virus, Hepatitis B virus, Hepatitis A virus, Hepatitis E virus, Human cytomegalovirus, Epstein-Barr virus, Herpes simplex viruses, and measles-, dengue- and rubella- viruses. Although it is not expected that current wet sampling techniques will be replaced by the use of DBSs, this method allows sampling in individuals and settings with difficult access and/or a lack suitable storage facilities [13]. Indeed, the DBS method is a minimally invasive and more economic sampling method that is readily available and that facilitates sample collection and storage. It involves the collection of capillary blood from a fingerstick onto a protein-saver card, which is then airdried and stored until processing. DBS samples can be stored and transported for testing at a later date, which may also provide enhanced surveillance in resourcelimited settings [14].

In the current study, the accuracy of the IgG determination from DBS samples was assessed before the determination of rubella seroprevalence. The main limitations of this evaluation were the number of samples tested, which were lower than initially planned, and the fact that immunity by vaccination may not be similar to immunity by natural infection. In fact, children from São Tomé and Príncipe had higher average IgG results than Portuguese children (respectively 89.35 and 50.9; $p$ $=0.034$, data not presented). Despite these limitations, the results suggest that the determination of IgG for the rubella virus in DBS had a good correlation with the standard method. These results are in accordance with a previous publication that showed no significant differences in the antibody concentrations in paired serum- 
Table 1 General characteristics of the São Tomé and Príncipe population

\begin{tabular}{|c|c|c|c|c|}
\hline & $\begin{array}{l}\text { Total } \\
(n=303)\end{array}$ & $\begin{array}{l}\text { Control Gr } \\
(171-56.4 \%)\end{array}$ & $\begin{array}{l}\text { Case Gr } \\
(132-43.6 \%)\end{array}$ & $p$-Value \\
\hline Age range & & & & 0.359 \\
\hline $\begin{array}{l}{[2-14]} \\
{[15-35]}\end{array}$ & $\begin{array}{l}147(48.5 \%) \\
156(51.5 \%)\end{array}$ & $\begin{array}{l}79(46.2 \%) \\
92(53.8 \%)\end{array}$ & $\begin{array}{l}68(51.5 \%) \\
64(48.5 \%)\end{array}$ & \\
\hline Mean Age SD & $17.31 \pm 9.722$ & $17.73 \pm 9.729$ & $16.77 \pm 9.723$ & \\
\hline Gender & & & & 0.391 \\
\hline $\begin{array}{l}\text { Male } \\
\text { Female }\end{array}$ & $\begin{array}{l}137(45.2 \%) \\
166(54.8 \%)\end{array}$ & $\begin{array}{l}81(47.4 \%) \\
90(52.6 \%)\end{array}$ & $\begin{array}{l}56(42.4 \%) \\
76(57.6 \%)\end{array}$ & \\
\hline Resident District & & & & $0.061^{*}$ \\
\hline $\begin{array}{l}\text { Água Grande } \\
\text { Mezochi } \\
\text { Cantagalo } \\
\text { Caué } \\
\text { Lemba } \\
\text { Lobata } \\
\text { Príncipe }\end{array}$ & $\begin{array}{l}174(57.4 \%) \\
47(15.5 \%) \\
17(5.6 \%) \\
23(7.6 \%) \\
6(2 \%) \\
19(6.3 \%) \\
17(5.6 \%)\end{array}$ & $\begin{array}{l}110(64.3 \%) \\
17(9.9 \%) \\
8(4.7 \%) \\
12(7 \%) \\
3(1.8 \%) \\
11(6.4 \%) \\
10(5.8 \%)\end{array}$ & $\begin{array}{l}64(48.5 \%) \\
30(22.7 \%) \\
9(6.8 \%) \\
11(8.3 \%) \\
3(2.3 \%) \\
8(6.1 \%) \\
7(5.3 \%)\end{array}$ & \\
\hline Spoken Language & & & & 0.0001 \\
\hline $\begin{array}{l}\text { Yes } \\
\text { No } \\
\text { Undefined }\end{array}$ & $\begin{array}{l}242(86.7 \%) \\
37(13.3 \%) \\
24\end{array}$ & $\begin{array}{l}161(97.6 \%) \\
4(2.4 \%) \\
6\end{array}$ & $\begin{array}{l}81(71.1 \%) \\
33(28.9 \%) \\
18\end{array}$ & \\
\hline Family History of $\mathrm{HL}$ & & & & 0.207 \\
\hline $\begin{array}{l}\text { Yes } \\
\text { No } \\
\text { Missing }\end{array}$ & $\begin{array}{l}52(17.5 \%) \\
245(82.5 \%) \\
6\end{array}$ & $\begin{array}{l}33(20 \%) \\
132(80 \%) \\
6\end{array}$ & $\begin{array}{l}19(14.4 \%) \\
113(85.6 \%)\end{array}$ & \\
\hline Consanguinity & & & & 0.461 \\
\hline $\begin{array}{l}\text { Yes } \\
\text { No } \\
\text { Missing }\end{array}$ & $\begin{array}{l}7(2.4 \%) \\
285(97.6 \%) \\
11\end{array}$ & $\begin{array}{l}3(1.8 \%) \\
162(98.2 \%) \\
6\end{array}$ & $\begin{array}{l}3(3.1 \%) \\
123(96.9 \%) \\
5\end{array}$ & \\
\hline Rubella IgG & & & & 0.085 \\
\hline $\begin{array}{l}\text { Positive } \\
\text { Negative } \\
\text { Borderline }\end{array}$ & $\begin{array}{l}202(66.7 \%) \\
101(33.3 \%) \\
12\end{array}$ & $\begin{array}{l}107(62.6 \%) \\
64(37.4 \%)\end{array}$ & $\begin{array}{l}95(72 \%) \\
37(28 \%)\end{array}$ & \\
\hline
\end{tabular}

Abbreviations: $S D$ standard deviation

${ }^{*}$ Chi-square Test by Monte Carlo Simulation; Bold: Total sample; Italic: $p$-Value; Italic bold: statistic significant $p$-Value

DBS samples, [15] although in our study, only the qualitative correlation is presented. Actually, quantitative DBS samples were also previously tested for the diagnosis of rubella during an outbreak, with an excellent correlation with the determination in serum, provided that

Table 2 Sample description of the case/control group and rubella lgG in the different age ranges

\begin{tabular}{lllll}
\hline & $\begin{array}{l}\text { Total } \\
(n=303)\end{array}$ & $\begin{array}{l}\text { IgG Pos } \\
(117-58.8 \%)\end{array}$ & $\begin{array}{l}\text { IgG Neg } \\
(82-41.2 \%)\end{array}$ & -Value \\
\hline Age range & & & & $\mathbf{0 . 0 2 5}$ \\
$\quad[2-14]$ & $\mathbf{1 4 7}(\mathbf{4 8 . 5 \% )}$ & 74 & 73 & \\
$\begin{array}{l}\text { Control group } \\
\text { Case group }\end{array}$ & 79 & $33(44.6 \%)$ & $46(63 \%)$ & \\
Age range & 68 & $41(55.4 \%)$ & $27(37 \%)$ & \\
$\quad$ [15-35] & $\mathbf{1 5 6 ( 5 1 . 5 \% )}$ & 128 & 28 & 0.528 \\
Control group & 92 & $74(57.8 \%)$ & $18(63.3 \%)$ & \\
Case group & 64 & $54(42.2 \%)$ & $10(35.7 \%)$ & \\
\hline
\end{tabular}

Bold: Total sample; Italic: $p$-Value; Italic bold: statistic significant $p$-Value the DBS indeterminate results were positive [16]. In addition, this methodology was used for the diagnosis of congenital rubella syndrome in another study, by detecting rubella IgM and IgG (the last in $\geq 6$ months old infants) in DBS, although in this study, the comparison was not performed with the reference sample, serum, but with oral fluid samples [17]. Therefore, using DBS for serology determinations seems to be an appropriate and useful approach, particularly in countries where routine immunization is not performed, to estimate the rate of infection with the wild-type rubella virus.

The prevalence of IgG in the population from São Tomé and Príncipe of 303 individuals from 2 to 35 years of age was $66.7 \%$, confirming that rubella infections are still very common in this country. In the group of children under 14 years of age, the prevalence of immunity to rubella was $50.3 \%$ (74/147 subjects), while in the age group between 15 and 35 years of age, the prevalence increased by up to $82.1 \%(128 / 156$ subjects. This increase 
Table 3 Binary Logistic Regression between Rubella and HL with and without factors (age group)

\begin{tabular}{|c|c|c|c|c|c|c|}
\hline & Cases $n(\%)$ & Controls n (\%) & $P$-value & Crude OR $(95 \% \mathrm{Cl})$ & $P$-value & Adjusted OR (95\% Cl) \\
\hline \multicolumn{7}{|l|}{ Age group } \\
\hline & & & 0.359 & & 0.111 & \\
\hline $\begin{array}{l}{[2-14]} \\
{[15-35]}\end{array}$ & $\begin{array}{l}68(51.5 \%) \\
64(48.5 \%)\end{array}$ & $\begin{array}{l}79(46.2 \%) \\
92(53.8 \%)\end{array}$ & & $\begin{array}{l}\text { Reference } \\
0.808 \text { [0.513-1.274] }\end{array}$ & & $\begin{array}{l}\text { Reference } \\
0.672 \text { [0.412-1.096] }\end{array}$ \\
\hline \multicolumn{7}{|l|}{ Rubella IgG } \\
\hline & & & 0.086 & & 0.032 & \\
\hline Negative & $37(28 \%)$ & $64(37.4 \%)$ & & Reference & & Reference \\
\hline Positive & 95 (72\%) & $107(62.6 \%)$ & & $1.536[0.941-2.507]$ & & $1.776[1.050-3.004]$ \\
\hline
\end{tabular}

Abbreviations: HL normal hearing - 0 - Reference Category is a response variable, independent variables Rubella lgG (0 -Negative, 1- Positive), age groups (0 - [2-14] years, 1 - [15-35] years); Italic: $p$-Value; Italic bold: statistic significant $p$-Value

suggests that women of child-bearing age are still suffering from rubella primary infections, and 18\% of these women are at risk for rubella infection during pregnancy and subsequent CRS/birth defects in their children.

Interestingly, an association between seroprevalence and SNHL was observed in the younger group (children $<14$ years, $p=0.025$ ), but in the older group ( $>14$ years, $p=0.528$ ). While congenital rubella infection is a known cause of deafness, the relationship between postnatal acquired infection and hearing loss is not proven, although a few reports suggest that it may occasionally occur [18, 19]. In this study, it was not possible to conclude how many cases of HL are attributable to rubella infection because the time of infection cannot be determined. Therefore, the rate of positive IgG infection resulting from congenital infections is not known, although the probability of infection during the gestational period is higher in the youngest group. The detection of rubella IgM in DBS from newborns will help to clarify this key question. This will be part of a future project of our team.

The development of oral language is dependent of the hearing status. Therefore, we found an expected higher prevalence of "no oral language" in the case group than in the control group.

According to the CDC, the rubella vaccine may be administered in combination with the mumps vaccine or the measles and mumps vaccine [20]. These should be administered at 12 to 15 months of age, with a second dose given at 4 to 6 years of age. However, given the need to control the transmission of rubella during pregnancy, vaccination of female children between 10-12 years of age and women of childbearing age is also recommended. The rubella vaccine has been shown to be effective without significant side effects and should thus be quickly implemented in the population of São Tomé and Príncipe as well as other African countries in which the rubella vaccine is not currently implemented and where there is an increase of SNHL [4].

The combined vaccine with the measles and mumps vaccine would be advantageous because these two pathologies can also unleash SNHL in the course of the disease [20].

\section{Conclusion}

Rubella is a preventable disease. Currently, most of the African countries do not use this vaccine.

Rubella infections are still very common in São Tomé and Príncipe, and women of child-bearing age are still at risk of rubella infection during pregnancy and subsequent CRS/birth defects of their children, justifying the urgency of vaccination against rubella.

According to the results obtained, a statistically significant association between the group of children under 14 years of age with SNHL and immunity for rubella was observed in this country. However, this study did not permit us to establish a cause-effect relationship between rubella infection and SNHL. Therefore, another study aiming to screen newborns for congenital rubella infection and to follow them for audiometric assessment is critical to determine the real impact of this infection in this African country.

\section{Abbreviations}

CDC: Centre of Diseases Control; Cl: Confidence interval; CRS: Congenital Rubella Syndrome; DBS: Dried blood spot; HL: Hearing loss; IMVF: Institute Marquês Valle Flor; OR: Odds ratio; SNHL: Sensorineural hearing loss; SPSS: Statistical package for the social sciences; WHO: World Health Organization

\section{Acknowledgements}

The authors would like to thank Democratic Republic of São Tomé and Príncipe, Instituto Marquês de Valle Flôr (IMVF), Instituto Camões, NOVA University School_Faculdade de Ciências Médicas de Lisboa, Fundação Calouste Gulbenkian, Mota\&Engil, José de Mello Saúde and Audiologists from Hospital CUF Infante Santo (Diogo Ribeiro, Tânia Martins and Vera Lourenço), and Institut Virion\Serion Gmbh (for their technical support concerning the ELISA Kit).

This project was part of a PhD thesis for the first author, with a research Grant from Jose de Mello Saúde.

The authors warmly dedicate this study to the memory of their colleague and friend Prof. Jorge Gaspar (1963-2015), who contributed so much of his knowledge and vision to this study.

This manuscript was edited for English language by American Journal Experts (AJE). 


\section{Funding}

Jose de Mello Saúde PhD Grant-to data collection and analysis.

\section{Availability of data and materials}

Data supporting findings can be found in: http://comum.rcaap.pt/handle/ 10400.26/5369 after publication.

\section{Authors' contributions}

CC, PP, MJC, and JP designed the study. CC, W and PC analysed the data and wrote the manuscript. PC, HC, SNS, MJC, PP and JP gave essential feedback on all versions of the manuscript. All authors have read and approved the final version of the manuscript.

\section{Competing interests}

The authors declare that they have no competing interests.

\section{Consent for publication}

"Not applicable".

\section{Ethics approval and consent to participate}

The project was submitted and approved by the Medical Ethics Committee of STP and Ethics Research Committee NMSIFCM-UNL (n02/2014/CEFCM). The Ethics Research Committee is aligned with the Declaration of Helsinki for the Protection of Human Subjects. A full written consent process was applied for all participants. Consent to use the survey data was also obtained.

\section{Author details}

'Otolaryngology Department, NOVA Medical School/Faculty of Medical Sciences, Universidade Nova de Lisboa, Campo dos Mártires da Pátria, 130, 1169-056 Lisboa, Portugal. ${ }^{2}$ Hospital CUF Infante Santo, Avenida Infante Santo, 34, 6 1350-079 Lisboa, Portugal. ${ }^{3}$ Centre for Toxicogenomics and Human Health (ToxOmics), NOVA Medical School / Faculty of Medical Sciences, Universidade Nova de Lisboa, Campo dos Mártires da Pátria, 130, 1169-056 Lisboa, Portugal. ${ }^{4}$ CEDOC, NOVA Medical School/ Faculty of Medical Sciences, Universidade Nova de Lisboa, Lisboa, Portugal. ${ }^{5}$ Escola Superior de Tecnologia da Saúde de Lisboa, Avenida D. João II, Lote 4.69.01, 1990-096 Lisboa, Portugal. ${ }^{6}$ BiolSI-Biosystems and Integrative Sciences Institute, Faculty of Science of the University of Lisbon, Lisbon, Portugal. ${ }^{7}$ ESS/IPS, School of Health, Polytechnic Institute of Setúbal, Setúbal, Portugal. ${ }^{8}$ Clinical Pathology Laboratory-Labco, Hospital da Luz, Avenida Lusíada, 100, 1500-650 Lisboa, Portugal.

Received: 25 March 2016 Accepted: 27 January 2017

Published online: 01 February 2017

\section{References}

1. Centers for Disease Control and Prevention. Rubella Virus. Epidemiol. Prev. Vaccine-Preventable Dis. 13th Ed. [Internet]. 2015; April:325-40. Available from: http://www.cdc.gov/vaccines/pubs/pinkbook/downloads/rubella.pdf.

2. Best JM, Reef S. The Immunological Basis for Immunization Series. Immunol. Basis Immun. Ser. - Modul. 11 Rubella. 2008;1-24. Available from: http:// apps.who.int/iris/bitstream/10665/43922/1/9789241596848_eng.pdf.

3. da Silva LPA, Queiros F, Lima I. Etiology of hearing impairment in children and adolescents of a reference center APADA in the city of Salvador, state of Bahia. Braz J Otorhinolaryngol. 2006;72:33-6. Available from: http://www. ncbi.nlm.nih.gov/pubmed/16917550.

4. Lasisi OA, Ayodele JK, ljaduola GTA. Challenges in management of childhood sensorineural hearing loss in sub-Saharan Africa, Nigeria. Int J Pediatr Otorhinolaryngol. 2006;70:625-9.

5. WHO. Immunization, Vaccines and Biologicals - Rubella and Congenital Rubella Syndrome (CRS) [Internet]. World Heal. Organ. 2015 [cited 2015 Oct 9]. p. 1-2. Available from: http://www.who.int/immunization/monitoring_ surveillance/burden/vpd/surveillance_type/passive/rubella/en/.

6. Grant GB. Global Progress Toward Rubella and Congenital Rubella Syndrome Control and Elimination-2000-2014No Title [Internet]. Ctr Dis Control Prev 2015 [cited 2016 Nov 21]. Available from: http://www.cdc.gov/ mmwr/preview/mmwrhtml/mm6437a5.htm

7. WHO Media centre. Media centre - Rubella [Internet]. World Heal. Organ. 2015 [cited 2015 Oct 24]. p. 1-3. Available from: http./www who.int/ mediacentre/factsheets/fs367/en/
8. Control EC for DP and. Measles and rubella monitoring October 2015. Reporting on surveillance data October 2014 to September 2015 and epidemic intelligence data to the end of October 2015. Stockholm: ECDC; 2015.

9. Caroça C, Campelo P, Ribeiro D, Lourenço V, Martins T, Caria H, et al. Hearing loss in Sao Tome and Principe - 2 Years of Humanitarian Missions. Rev Port Otorrinolaringol e Cir Cérvico-Facial. 2016;54:5-11.

10. WHO. Immunization Profile - Sao Tome and Principe [Internet]. 2013 [cited 2013 Apr 27]. p. 1-12. Available from:http://apps.who.int/immunization_ monitoring/globalsummary/countries?countrycriteria\%5Bcountry\%5D\% 5B\%5D=STP\&commit=OK.

11. Gorga MP, Johnson TA, Kaminski JK, Beauchaine KL, Cassie A, Neely ST. Using a combination of click- and toneburst-evoked auditory brainstem response measurements to estimate pure-tone thresholds. Ear Hear. 2006; 27:60-74.

12. WHO. Prevention of blindness and deafness - Grades of hearing impairment [Internet]. WHO. 2013 [cited 2013 Apr 28]. Available from: http://www.who. int/pbd/deafness/hearing_impairment_grades/en/.

13. Snijdewind IJM, van Kampen JJA, Fraaij PLA, van der Ende ME, Osterhaus ADME, Gruters RA. Current and future applications of dried blood spots in viral disease management. Antiviral Res. 2012;93:309-21. Available from: http://linkinghub.elsevier.com/retrieve/pii/S016635421100547X.

14. Dokubo EK, Evans J, Winkelman V, Cyrus S, Tobler LH, Asher A, et al. Comparison of Hepatitis C Virus RNA and antibody detection in dried blood spots and plasma specimens. J Clin Virol. 2014;59:223-7. Available from: http://www.ncbi.nlm.nih.gov/pubmed/24529844.

15. Hardelid P, Williams D, Dezateux C, Cubitt WD, Peckham CS, Tookey PA, et al. Agreement of rubella lgG antibody measured in serum and dried blood spots using two commercial enzyme-linked immunosorbent assays. J Med Virol. 2008;80:360-4. Available from: http://doi.wiley.com/10.1002/jmv. 21077.

16. Helfand RF, Cabezas C, Abernathy E, Castillo-Solorzano C, Ortiz AC, Sun H, et al. Dried Blood Spots versus Sera for Detection of Rubella Virus-Specific Immunoglobulin M (IgM) and IgG in Samples Collected during a Rubella Outbreak in Peru. Clin Vaccine Immunol. 2007;14:1522-5. Available from: http://cvi.asm.org/cgi/doi/10.1128/CVI.00144-07.

17. Adam O, Ali AK, Hübschen JM, Muller CP. Identification of congenital rubella syndrome in Sudan. BMC Infect Dis. 2014;14:305. Available from: http:// bmcinfectdis.biomedcentral.com/articles/10.1186/1471-2334-14-305.

18. Hulbert TV, Larsen RA, Davis CL, Holtom PD. Bilateral hearing loss after measles and rubella vaccination in an adult. N Engl J Med. 1991;325:134 Available from: http://www.ncbi.nlm.nih.gov/pubmed/2052052.

19. Kobayashi H, Suzuki A, Nomura Y. Unilateral hearing loss following rubella infection in an adult. Acta Otolaryngol Suppl. 1994;514:49-51. Available from: http://www.ncbi.nlm.nih.gov/pubmed/8073885.

20. Centers for Disease Control and Prevention. Prevention of measles, rubella, congenital rubella syndrome, and mumps, 2013: summary recommendations of the Advisory Committee on Immunization Practices (ACIP). MMWR. 2013:62:1-34.

\section{Submit your next manuscript to BioMed Central and we will help you at every step:}

- We accept pre-submission inquiries

- Our selector tool helps you to find the most relevant journal

- We provide round the clock customer support

- Convenient online submission

- Thorough peer review

- Inclusion in PubMed and all major indexing services

- Maximum visibility for your research

Submit your manuscript at www.biomedcentral.com/submit
Biomed Central 